\title{
Review \\ Angiotensins and Alzheimer's disease: a bench to bedside overview
}

\author{
Patrick G Kehoe
}

\begin{abstract}
Dementia Research Group, Institute of Clinical Neurosciences, Department of Clinical Science at North Bristol, University of Bristol, Frenchay Hospital, Bristol BS16 1LE, England, UK
\end{abstract}

Corresponding author: Patrick G Kehoe, Patrick.Kehoe@bristol.ac.uk

Published: 9 July 2009

This article is online at http://alzres.com/content/1/1/3

(c) 2009 BioMed Central Ltd

Alzheimer's Research \& Therapy 2009, 1:3 (doi:10.1186/alzrt3)

\begin{abstract}
The pathology of Alzheimer's disease (AD) features amyloid $\beta$ peptide deposition, intracellular neurofibrillary tangles and deficits in the cholinergic pathway. Abnormal blood pressure is recognised as a risk factor for the development of $A D$, although the underlying mechanisms remain unproven. This review proposes angiotensins and associated enzymatic pathways as important mediators of recognised but undefined links between blood pressure and $A D$. Evidence in support of this involvement translates consistently from the most basic in vitro, in vivo and ex vivo experimental paradigms to more complex human-based observational and experimental studies, which also fortunately offer potential for therapeutic interventions against $A D$.
\end{abstract}

\section{Prevailing hypotheses of Alzheimer's disease pathogenesis}

Alzheimer's disease (AD) [MIM 104300], as the most common form of progressive dementia, is characterised neuropathologically by the presence of intracellular neurofibrillary tangles and features resulting from the deposition of amyloid $\beta$-peptide (A $\beta$ ) extracellularly in the form of senile plaques and within blood vessels in the brain in the form of cerebral amyloid angiopathy. The pathogenesis of $A D$ is understood to be partly explained by mechanisms involved with (but not restricted to) two of the most prevailing hypotheses: the $A \beta$ cascade hypothesis and the cholinergic hypothesis. The $A \beta$ cascade hypothesis, which developed in the early 1980s, suggests that the commonly observed neurodegenerative abnormalities of $A D$, particularly senile plaques, develop following the accumulation of the 39 to 42 amino acid peptide $A \beta$ in the brain [1]. This accumulation of $A \beta$ is likely a consequence of imbalance between production of $A \beta$ from amyloid precursor protein (APP; Figure 1) and its removal. $A \beta$ removal can be mediated via drainage through interstitial fluid in the space surrounding blood vessels in the brain, by receptor-mediated transport of $A \beta$ from the brain to the peripheral circulation, by enzymatic degradation or various combinations of all the these [1]. Over the years the $A \beta$ hypothesis has not been universally accepted due to its perceived failing that brain $A \beta$ deposition correlated poorly with cell death or disease severity in $A D$ whereas neurofibrillary tangle pathology, another established neuropathological hallmark for $A D$, correlated better and, as such, was suggested to be more relevant, with $A \beta$ representative of a secondary phenomenon [2]. Yet this failing was arguably addressed in the past decade with the identification of soluble and diffusible oligomeric forms of $A \beta$ that are now thought to be the more harmful forms and which have been correlated with $A D$ pathogenesis [3]. Furthermore, questions have now arisen as to whether neurofibrillary tangles are merely a marker of disease progression and not, in fact, a mediator of cell death as has been proposed (see $[3,4]$ for reviews).

The cholinergic hypothesis posits that loss of cholinergic function (derived from the action of the neurotransmitter acetylcholine $(A C h))$ in the central nervous system is a significant part of the cognitive decline associated with $A D$ (see [5] for a review; Figure 1). This hypothesis pre-dates the seeds of the $A \beta$ cascade hypothesis but is supported by considerable evidence that there is reduced synthesis and altered transport of $\mathrm{ACh}$, selective loss of cholinergic neurons, disruption of $\mathrm{ACh}$ receptor signalling, as well as reductions in the levels of these receptors in AD brains (see [5] for a review). Indeed, the majority of licensed 'cholinesterase' therapeutics currently used to treat and partially delay some of the progressive symptoms of $A D$ are drugs that target acetylcholinesterase-mediated breakdown of ACh, thereby increasing the amount and prolonging the life of $\mathrm{ACh}$ in the brain [5]. Importantly, neither of the properties of these hypotheses exist in isolation and there is now a body of

$\mathrm{A} \beta=$ amyloid $\beta$ peptide; $\mathrm{ACE}=$ angiotensin-1 converting enzyme; $\mathrm{ACE}-\mathrm{I}=\mathrm{ACE}$ inhibitor; $\mathrm{ACh}=$ acetylcholine; $\mathrm{AD}=\mathrm{Alzheimer}$ 's disease; $\mathrm{Ang}=$ angiotensin; APP = amyloid precurser protein; $\mathrm{ARB}=$ angiotensin receptor blocker; $\mathrm{AT}_{1} \mathrm{R}_{\mathrm{AT}} \mathrm{R}=$ angiotensin $\|$ receptors; $\mathrm{BBB}=$ blood brain barrier; $\mathrm{CSF}=$ cerebrospinal fluid; Indel $=$ insertion/deletion polymorphism; RAS $=$ renin angiotensin system. 


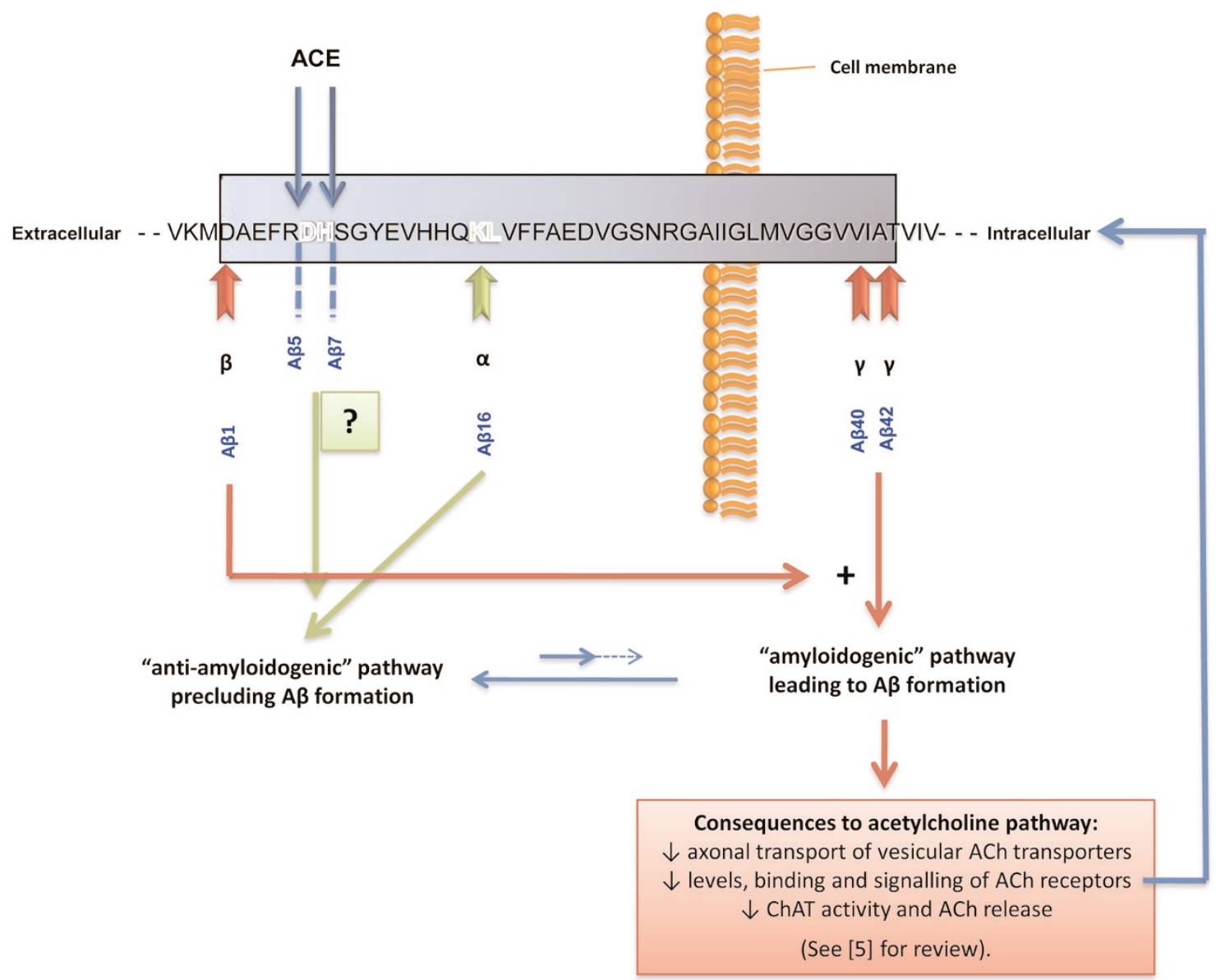

Schematic of amyloid precurser protein metabolism, from which amyloid $\beta$ peptide can be produced. The amyloid precurser protein (APP) amino acid sequence is given in the single letter code with the boxed sequence representing the amyloid $\beta$ peptide (A $\beta$ ). The red arrows denoted by $\beta$ and $\gamma$ represent the major $\beta$ - and $\gamma$-secretase cleavage sites on APP from which A $\beta$ is produced in the amyloidogenic pathway. The green arrow denoted by $\alpha$ pointing to the highlighted lettering shows the vicinity of the major $\alpha$-secretase site on APP, which precludes the formation of APP in the anti-amyloidogenic pathway. The blue arrows labelled ACE show the proposed amino acids that are involved in (anti-amyloidogenic denoted by a question mark) ACE-mediated cleavage of $A \beta$, which were suggested to be either Asp ${ }^{7}-S_{e r}{ }^{8}$ based on the detection of $A \beta 8-40$ fragments or $\mathrm{Arg}^{5}-\mathrm{His}^{6}[8,32]$. Interestingly, isomerisation (that is, having the same molecular formula but having a different structure and sometimes different properties) of the $\mathrm{Asp}^{7}$ (isoAsp ${ }^{7}$ ) residue of $A \beta$, a common age-related and possible conformational modification that is more prevalent in Alzheimer's disease (AD), resulted in more efficient cleavage than the non-modified Asp ${ }^{7}$ in vitro. It has thus been suggested that the main cleavage site of angiotensin-1 converting enzyme could be $\mathrm{Arg}^{5}-\mathrm{His}^{6}$ and the identification of A $\beta 8-40$ cleavage products detected previously might be the result of subsequent hydrolysis of A $\beta 6-40$ fragments. The blue horizontal arrows of different sizes and pointing in opposite directions indicate that the majority of APP processing throughout a lifetime is anti-amyloidogenic but that in AD there is evidence of some increased amyloidogenic processing (denoted by the dashed arrow). Negative effects on the cholinergic pathway resulting from A $\beta$ activity are shown, as are reported complex feedbacks between cholinergic receptors and APP processing (see [5] for a review). ChAT, choline acetyltransferase.

evidence supporting complex levels of interaction between the two and, more than likely, with other systems that fall beyond the scope of this review (see [5] for a review; Figure 1).

\section{The renin angiotensin system}

The renin angiotensin system (RAS) is best known for its role in the kidney in controlling blood pressure and bodily fluid homeostasis. The 'classical' RAS is known by the role of renin in cleaving inactive angiotensinogen to produce angiotensin (Ang)l, which is, in turn, converted by angiotensin-1 converting enzyme (ACE) to the (vaso-)active Angll [6]. Angll exerts its well known hypertensive effects following binding to its two receptors $\left(A T_{1} R\right.$ and $\left.A T_{2} R\right)$ [7]. However, the past two decades have revealed that the classical RAS was only the tip of the iceberg of what is now known to be a very complex system involving new Angl and Angll metabolites, additional receptors and regulating mechanisms (see [7] for a review; Figure 2). This added complexity has also offered new potential therapeutic targets for hypertension in addition to those already targeting the RAS through inhibition of ACE (ACE inhibitors 


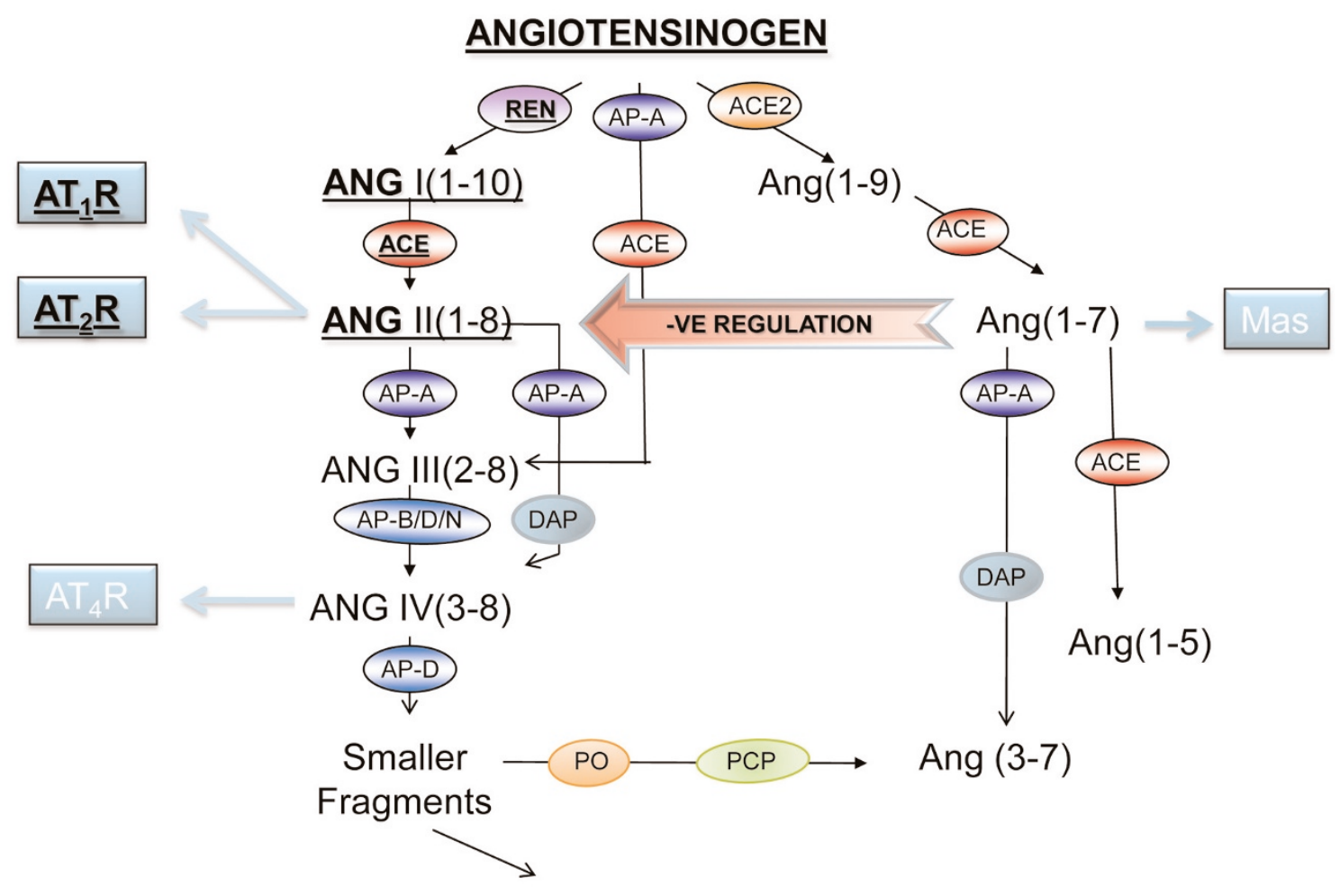

Degraded or inactive oligopeptides?

\begin{abstract}
Schematic representation of the renin angiotensin system. Additional components of the renin angiotensin system (RAS) pathway have been identified in recent years, increasing its complexity. The 'classical' components of the system are highlighted in bold and by underlined text (modified from [8] and incorporating parts of the discussion from [50]). Angiotensin metabolites are prefixed by Ang, with the number of amino acids present relative to the 14 amino acid angiotensinogen sequence order. Black arrows between peptide fragments denote enzymatic conversion steps catalyzed by a host of enzymes denoted in coloured circles or boxes according to the abbreviations listed below. Blue arrows from peptides to blue boxes denote receptor binding routes according to the main text. Note that the Angll metabolite Anglll is currently considered to be the main and a more potent mediator of many recognised Angll functions [50], and the binding of AnglV to its receptor is believed to affect cognitive function [40]. Also note the ACE2-Ang(1-7)-Mas (receptor) axis, which is now currently believed to be a RAS internal regulatory mechanism to attenuate Angll-mediated functions (large red arrow centrally located in pathway; ACE2 is a recently discovered ACE homologue) [50]. Abbreviations: ACE, angiotensin-1 converting enzyme; AP, aminopeptidase; DAP, dipeptidyl aminopeptidase; PCP, carboxypeptidase; PO, propyl oligopeptidase; REN, renin.
\end{abstract}

(ACE-Is)) or by preventing Angll from binding its receptors (angiotensin receptor blockers (ARBs)) [8] (Figure 2).

\section{The relevance of the renin angiotensin system to Alzheimer's disease Epidemiological clues?}

Hypertension is a recognised risk factor for cerebrovascular disease, coronary heart disease and increased cardiovascular morbidity and mortality [9] and its treatment with drugs such as RAS-acting ACE-ls and ARBs lessens morbidity and mortality and improves quality of life and preserves cognitive function [10]. Like dementia, hypertension incidence increases with age and is thought to affect almost half of people aged over 70 years [9]. The association between hypertension and dementia appears to be more than coincidental and the balance of findings from longitudinal and cross-sectional studies suggest that elevated mid-life blood pressure precedes the development of $A D$, although in the years preceding dementia onset the hypertension appears to lessen [9]. This observation has been suggested to be a secondary phenomenon [9], possibly due to hypertension related pathologies that interestingly are also relevant in $A D$ [11]. Indeed, some studies have reported hypertension related elevations in neurofibrillary tangle numbers and atrophy in the regions of the brain relevant to $A D$ (reviewed by Papademetriou [10]); however, apart from these findings any other mechanistic links between hypertension and $A D$ have been lacking. 


\section{The involvement of renin angiotensin system genes in Alzheimer's disease}

With the exception of a single study of hypertensionassociated genetic variants in the renin and angiotensinogen genes that found no association with $A D$, the bulk of investigations of RAS genes for $A D$ susceptibility have focussed on $A C E 1$, which encodes the RAS rate-limiting enzyme ACE [12]. ACE1 is interesting because of the role of ACE in hypertension and vascular disease but also because previous studies on familial hypertension on a common Alu insertion/deletion (I/D; indel) polymorphism (rs1799752) within intron 16 of $A C E 1$ found this locus to be 'functionally associated' with plasma levels of ACE. The reputed functional association was such that homozygosity for the D and I alleles correlated with the highest and lowest levels of ACE, respectively, while heterozygotes had intermediate levels [13]. Current estimates are that ACE1 contributes to $20 \%$ of the total variation in serum ACE concentration and 16 to $24 \%$ of the variation in ACE activity, although the underlying mechanism for this association remains unclear since two functional sites within ACE1 might be involved [14].

The first positive association between the ACE1 indel and $A D$ was published in 1999, where ACE1 variants were associated with $A D$ independent of the already well recognised risks associated with variants in $A P O E$ (the gene encoding apolipoprotein E) [15]. Since then the balance of evidence from over 30 replication case-control studies and a number of meta-analyses, including that of the continually updated online meta-analyses 'AlzGene' database (gene ID 125) [12], continues to support a possible (albeit modest) correlation between ACE1 variation and risk of AD [12]. Studies of other $A C E 1$ variants that also 'tag' the previously reported $A D$ risk alleles have also supported $A C E 1$ involvement in $A D$, with reported association between extended $A C E 1$ variants (that is, haplotypes) and $A D$ risk, smaller brain hippocampal and amygdalar volumes, lower (less beneficial) levels of cerebrospinal fluid (CSF) $A \beta$ and age of $A D$ onset [15-18]. Further evidence supporting $A C E 1$ and $A D$ risk has come from a new generation of genome-wide association studies and from genes deemed to have the strongest 'signals' in the AlzGene database in large family-based and case-control studies. Generally, ACE1 consistently appeared to have some level of association that, in most cases, disappeared after various corrections for statistical analyses were made or only remained significant when secondary (for example, gene-gene interaction) analyses were conducted [16,18-20]. Although not all studies agree with the involvement of $A C E 1$ in $A D$ risk on the balance of current evidence, any genetic involvement of $A C E 1$ in $A D$ is likely modest, complex and requires interaction with other genes or factors $[15,19]$.

\section{Alzheimer's disease-related alterations to the renin angiotensin system}

Prior to any evidence of genetic association between ACE1 and $A D$, a limited number of small and methodologically diverse studies examined the vascular role of ACE and other RAS components in the central nervous system of $A D$ patients and controls. There have been various reports of increased ACE activity that correlated with mean $A \beta$ senile plaque load and Braak stages, increased ACE binding density, increased neuronal and perivascular ACE immunoreactivity - which was also found to correlate with levels of parenchymal $A \beta$ load and increased $A \beta$ deposition in blood vessels (that is, cerebral amyloid angiopathy) [21-23] (see $[23,24]$ for reviews) - as well as increased Angll and Angll receptor $\left(A T_{1} R, A T_{2} R\right)$ binding or immunoreactivity in $A D$ brain $[21,25]$. Other studies have reported reduced $A C E$ levels in CSF of AD patients [25,26], no differences in ACE activity or levels $[27,28]$ or elevated ACE activity [21]. Two studies reported no statistically significant associations but there were data trends between the presence $A C E 1$ indel risk genotypes and the 42 amino acid variant of $A \beta(A \beta 42)$ load in AD [29] and ACE protein level (but not ACE activity) in post mortem CSF from $A D$ patients [21]; the latter observation is consistent with the association between ACE1 indel variation and plasma ACE $[13,30]$, where ACE was also found to be reduced in AD patients [31]. There are some obvious disparities across the various studies, but these are likely explained by the variety of methodologies used over the years and, in some cases, relatively small sample numbers. On balance, in $A D$ there does appear to be either a primary (that is, potentially causative effect leading to AD) or secondary (that is, a manifestation arising from $A D$ pathogenesis) disturbance to components of the RAS.

\section{Renin angiotensin system function in cell-based and animal models of Alzheimer's disease}

The in vitro findings that the ACE-I lisinopril could interfere with ACE's ability to inhibit the aggregation, deposition and fibril formation of the 40 amino acid variant of $A \beta(A \beta 40)$, as well as to reduce $A \beta$-mediated toxic effects on rat cells, provided a possible model (that is, ACE can degrade $A \beta$ ) for $A C E$ involvement in $A D$. When the $A \beta$ degrading properties are viewed alongside the influence of $A C E 1$ variants on $A C E$ levels, it is possible to envisage a model whereby $A D$ associated $A C E 1$ risk variants that reduce plasma levels of ACE [13] - and possibly levels in the CSF [21] - could impact on a person's ability to degrade $A \beta$. Further cell-based and in vitro studies supported these findings (see [8] for further discussion), although there remains uncertainty as to the amino acids of $A \beta$ where ACE cleavage takes place and whether these sites are the same in vivo for full length $A \beta$ compared to some shorter $A \beta$ fragments on which experiments to identify the site of cleavage were conducted (Figure 1) [8,32].

Initial animal studies to test whether ACE-mediated $A \beta$ cleavage is evident in vivo and whether ACE-ls might interfere with $A \beta$ pathology found no supportive evidence [8]. However, subsequent studies found ACE-mediated enzymatic conversion of $A \beta 42$ to $A \beta 40$ and their subsequent 
degradation in mouse and human brain homogenates as well as increased $A \beta$ deposition in mice chronically administered the ACE-I captopril [33]. Transgenic mouse models of AD given the ARB valsartan also demonstrated improved spatial learning and attenuated oligomerisation of $A \beta$ [34], while low doses of the ARB olmesartan improved hippocampal synaptic plasticity and $A \beta$-mediated cerebrovascular dysfunction, which included impairment of the autoregulatory mechanisms involved with cerebral blood flow [35]. It has been suggested that the differences between these studies are not related to species-influenced differences in the degradation of human $A \beta$ (that is, from human transgenes in animal models) by mouse ACE [36]. A more likely explanation lies with differences in the experimental designs between the studies. Animals that commenced longer periods of treatment at a more mature age but prior to the development of $A \beta$ related pathology (possibly resembling middle age treatment for hypertension) tended to demonstrate evidence of ACEmediated $A \beta$ degradation and how ACE-ls might have adverse effects. Clearly, further studies are now needed given the potential significance of these findings.

\section{Effects of angiotensins and anti-angiotensin treatments on cognition}

Apart from the role of Angll in the development of essential hypertension, the angiotensins (Angll, Anglll and AnglV; Figure 2) acting on the angiotensin receptors $A T_{1} R$ and $A T_{2} R$ and the putative angiotensin receptor $\mathrm{AT}_{4} \mathrm{R}$ play a significant role in cognition and anxiety, detailed discussion of which is not possible in this article (see [37] for an overview). In addition to the potential of $A C E$ in mediating $A \beta$ degradation as a mechanism in $A D$, there are also data strongly suggesting that Angll inhibits potassium-mediated release of ACh from slices of rat entorhinal and human temporal cortex, demonstrating a specific interaction between angiotensin signalling and the cholinergic system [38]. Angll has also been shown to influence tumour necrosis factor $\alpha$ and transforming growth factor $\beta$ signalling, blood brain barrier (BBB) maintenance and cell survival (via $A T_{1} R$ and $A T_{2} R$ receptors and a positive effect on the activity of plasmin, another $A \beta$ degrading enzyme), all of which contribute to and are familiar aspects of $A D$ pathogenesis [39]. In addition to AD-associated alterations in Angll receptor immunoreactivity $[21,25]$, distorted neuronal processes in hippocampal Angllimmunopositive cells in senile plaques [23], and the growing literature that the Angll metabolite AngIV may offer additional glucose transport linked therapeutic routes to improve cognition (see [40] for discussion), it is clear that Angll and its signalling pathway through its receptors are implicated in a number of facets of $A D$ pathogenesis.

The significance of these properties is further emphasised by the likely links between hypertension and dementia and, unsurprisingly, has led over the years to the consideration of how anti-hypertensive treatments (ACE-ls and ARBs) acting on the RAS might affect cognition. Secondary analyses of data between two large clinical trials to reduce the incidence of stroke - the Systolic Hypertension in Europe (SYST-EUR) trial (involving the ACE-I enalapril) and the Perindopril Protection Against Recurrent Stroke Study (PROGRESS) trial (involving the ACE-I perindopril) - found that the ACE-Is reduced dementia and cognitive decline [8]. However, perindopril inclusion in addition to indapamide in the Hypertension in the Very Elderly Trial Cognitive Function Assessment (HYVET-COG) trial made no difference to dementia incidence [41]. Similarly, ACE-ls did not demonstrate any protective benefit or other effects [42] in a recent prospective study of new patients from a population in which a prior retrospective analysis of the impact of antihypertension medication use and incidence of dementia found that ACE-ls demonstrated a trend towards incidence of $A D$ (adjusted hazard ratio $=1.13$ ) despite anti-hypertensive treatments in general being protective against $A D$ [8]. Moreover, although the majority of existing data from observational studies and secondary outcomes of trials are derived from examination of ACE-Is on cognitive function, there are also data suggesting that any perceived cognitive benefits may be related more specifically to mechanisms involving Angll and/or its derivatives (Figure 2). Losartan, an ARB that can cross the BBB, was found to improve the cognitive function and quality of life in people with hypertension aged up to 73 years $[43,44]$ but also has been found to demonstrate positive benefits in both animal models and human paradigms of cognition and anxiety that appear to be independent of blood pressure changes and provide interesting starting points that have yet to be followed meaningfully in the context of $A D$ or other dementias (see [37] for an overview). Most studies to date suggest that antihypertensive treatments acting on the RAS are of potential use to reduce the incidence and/or rate of cognitive decline in dementia; however, they need further validation since in some of the previous studies the measures of cognition have been limited when compared to the standards that would be included in a trial designed for AD patients.

\section{Can renin angiotensin system-inhibiting medications be used to treat Alzheimer's disease?}

The potential benefits of ACE-ls in attenuating cognitive decline are further supported by several small and larger observational studies with more attention given to cognitive measures and the diagnosis of AD. Overall, most findings show that people taking $A C E$-ls had reduced incidence of $A D$ and that $A C E-I s$ reduced rates of cognitive decline in people with mild cognitive impairment $[8,45,46]$. However, the true test of the therapeutic potential of any drug is a clinical trial. With respect to specific studies of drugs acting on the RAS in $A D$, two pilot trials of the not commonly used BBBcrossing ACE-I ceranapril, which was shown to have delayed but long lasting inhibitory actions on ACE activity in rat brains, have been reported [47]. The first trial had a duration of 4 weeks and included 13 AD patients and 2 controls [48] and the second trial was for 15 weeks and was a double 
blind controlled three-way cross-over trial including 30 patients [49]; both found no benefits to the patients involved, although further analysis of the data from the second study suggested that a study of longer duration and/or with higher dosages was needed. Another 18-week cross-over trial of perindopril on cognition in 16 very elderly hypertensive people also found no treatment-related differences [50]. In contrast, a randomised, prospective three-arm parallel group trial conducted over 12 months on nearly 150 patients reported that the so-called brain penetrating ACE-Is captopril and perindopril reduced cognitive decline more effectively in mild to moderate $A D$ patients than the reputed non-brain penetrating ACE-ls enalapril or imidapril, which performed the same as the calcium channel blockers that served as the third arm in the trial. After 1 year, the average rate of decline in the perindopril/captopril-treated group was less than 1 Mini Mental State Examination (MMSE) point compared with changes of more than 4 points for the other two treatment groups over the same time scale (reviewed in [8]).

It is clear that findings of the larger studies offer more promising data and that there is now a need for further, more rigorous studies to be conducted as well as studies that examine ARBs in a similar context to offer meaningful comparisons between ACE-I- and ARB-mediated effects. Disparities between the earlier and later studies - apart from their size differences, which may be significant - include the duration of treatment and follow-up in patients but also perhaps to a lesser extent that the threshold measurement by which clinical hypertension is now diagnosed has been revised [44]. Indeed, a further aspect needing consideration in future trial designs is the peculiar relationship that exists between hypertension and AD where increased hypertension and serum cholesterol levels in midlife seem to be associated with an increased incidence of $A D$ in later life but also decreased blood pressure and serum cholesterol levels in later life appear to be associated with increased risk of $A D$ at a more advanced age [42]. This is further reinforced by the finding from a study including a wide age range of elderly subjects that the relationship between blood pressure and cognition is not linear and the suggestion that there could be an optimal level of blood pressure that supports optimal cognitive function and that deviation from this increases the likelihood or risk of cognitive decline [44].

\section{Issues in the clinical application of drugs affecting the renin angiotensin system}

Alterations in various RAS components have been observed consistently in various studies of AD. These consistent findings can be seen across a range of studies, from laboratory-based quantitative and qualitative investigations involving genetic association studies and histological or biochemical studies of human tissue samples through more manipulable experimental systems involving cells and animals to the most relevant population-based observational and clinical trial related studies. The ACE-mediated $A \beta$ degradation model is interesting, particularly if baseline ACE levels are genetically regulated. However, therein lies a possible contradiction as to how genetic predisposition to lower ACE levels or activity adversely affects ACE-mediated $A \beta$ degradation when $A C E-I s$, which also reduce $A C E$ activity, seem to be protective against both dementia and $A D$ incidence and cognitive decline (for a more in depth discussion, see [8]). This may be partly explained by the possibility that the association between ACE1 variation and ACE levels is, in fact, relatively weak or that there are overriding changes to the normal regulation of $A C E$ expression and activity secondary to $A D$ - or $A \beta$-related pathology. In support of the latter hypothesis, we and others have shown that there is elevated ACE activity in $A D$ brain tissue that appears to be independent of ACE1 variation and we have also reported that cultured neuronal cells treated with oligomeric $A \beta$ peptides displayed increased ACE activity after 24 hours [21]. Given the range of potentially deleterious effects that can be mediated by Angll (including depression of ACh release and inflammation), one can envisage possible consequences of over-production or post-translational modifications of ACE that could result in increased Angll production. It is also possible to see how various observational studies in mild cognitive impairment and $A D$ find $A C E-l s$ and $A R B$ s to be protective against $A D$ incidence and cognitive decline $[8,45,46]$. Other possible explanations for the observed alterations in cognitive function could be that the effects are driven by peripheral and not central effects and/or the drugs in question may not penetrate the BBB as well as originally thought, meaning that the potential for interrupting $A \beta$ degradation is less of an issue. It is possible that ACE, Angll or any of the other factors involved in the RAS, particularly the newly proposed internal regulatory mechanisms in the RAS thought to work in opposition to Angll [51] (Figure 2), may have yet-to-be-discovered functions within the brain.

What is also clear is that further clinical trials of ACE-ls or $A R B s$ in $A D$ are needed because, if these drugs are found to be beneficial, they then provide the benefit of being immediately available for, and amenable to, accelerated testing and progression through what is normally a lengthy drug discovery pipeline from initial compound discovery to eventual implementation. However, the potential of these compounds for use as symptomatic treatments will need to be investigated in ways that are mindful of the possible neuropathological consequences of using them if the results from recent animal studies also apply to humans (although this may not apply to ARBs) [33,34]. In addition to their use in $A D$, there is now also a significant need to clarify whether chronic use of ACE-Is, which offer a very effective means of treating hypertension, may have any possible negative consequences (for example, on a person's $A \beta$ degrading potential) for particular subgroups of people. If such were proven to be the case, then strong consideration will need to be given as to whether their use in hypertension treatment 
should be continued, especially when ARBs are a possibly preferable option as they may not interfere with ACE's degradation of $A \beta$.

\section{Conclusion}

Studies over the past two decades have added to our knowledge of the pathways involved in the pathogenesis of $A D$, including alterations to ACE and other angiotensinrelated components of the RAS. Whether these are primary mediators or secondary consequences of the disease still remains to be shown, however, and further studies are certainly needed. There may be insufficient evidence at this time with which to make a final judgement as to what benefit or consequences ACE-Is or ARBs have on the development or progression of $A D$, but there is sufficient evidence to justify more measured consideration when prescribing ARBs or ACE-Is for hypertension as well as active future study of how pharmacological targeting of Angll in this pathway could offer therapeutic value in mitigating against secondary pathogenic $A \beta$-mediated changes in AD.

\section{Competing interests}

The author declares that they have no competing interests.

\section{Acknowledgements}

The author is funded by the Sigmund Gestetner Foundation and would like to thank Dr Scott Miners for helpful comments on the manuscript.

\section{References}

1. Miners JS, Baig S, Palmer J, Palmer LE, Kehoe PG, Love S: Abeta-degrading enzymes in Alzheimer's disease. Brain Pathol 2008, 18:240-252.

2. Hardy J: Has the amyloid cascade hypothesis for Alzheimer's disease been proved? Curr Alzheimer Res 2006, 3:71-73.

3. Walsh DM, Selkoe DJ: A beta oligomers - a decade of discovery. J Neurochem 2007, 101:1172-1184.

4. Congdon $\mathrm{EE}$, Duff $\mathrm{KE}$ : Is tau aggregation toxic or protective? J Alzheimers Dis 2008, 14:453-457.

5. Pakaski M, Kalman J: Interactions between the amyloid and cholinergic mechanisms in Alzheimer's disease. Neurochem Int 2008, 53:103-111.

6. Miller SA, Accardi JR, St Onge EL: Angiotensin II vaccine: a novel approach in the treatment of hypertension. Expert Opin Biol Ther 2008, 8:1669-1673.

7. von Bohlen und Halbach O, Albrecht $D$ : The CNS reninangiotensin system. Cell Tissue Res 2006, 326:599-616.

8. Kehoe PG, Wilcock GK: Is inhibition of the renin-angiotensin system a new treatment option for Alzheimer's disease? Lancet Neurol 2007, 6:373-378.

9. Skoog I, Gustafson D: Update on hypertension and Alzheimer's disease. Neurol Res 2006, 28:605-611.

10. Papademetriou V: Hypertension and cognitive function. Blood pressure regulation and cognitive function: a review of the literature. Geriatrics 2005, 60:20-22, 24.

11. Skoog I, Gustafson D: Hypertension, hypertension-clustering factors and Alzheimer's disease. Neurol Res 2003, 25:675-680.

12. Bertram L, McQueen MB, Mullin K, Blacker D, Tanzi RE: Systematic meta-analyses of Alzheimer disease genetic association studies: the AlzGene database. Nat Genet 2007, 39:17-23. Accessed [30th March 2009]

13. Rigat B, Hubert C, Alhenc-Gelas F, Cambien F, Corvol P, Soubrier F: An insertion/deletion polymorphism in the angiotensin l-converting enzyme gene accounting for half the variance of serum enzyme levels. J Clin Invest 1990, 86:1343-1346.

14. McKenzie CA, Sinsheimer JS, Adeyemo AA, Cox RD, Southam L, Hugill A, Bouzekri N, Lathrop M, Forrester TE, Cooper RS, Ward
R: SNP haplotypes in the angiotensin l-converting enzyme (ACE) gene: analysis of Nigerian family data using gamete competition models. Ann Hum Genet 2005, 69:227-232.

15. Lehmann DJ, Cortina-Borja M, Warden DR, Smith AD, Sleegers $K$, Prince JA, van Duijn CM, Kehoe PG: Large meta-analysis establishes the ACE insertion-deletion polymorphism as a marker of Alzheimer's disease. Am J Epidemiol 2005, 162:305-317.

16. Kauwe J, Wang J, Mayo K, Morris J, Fagan A, Holtzman D, Goate A: Alzheimer's disease risk variants show association with cerebrospinal fluid amyloid beta. Neurogenetics 2009, 10:1317.

17. Meng $Y$, Baldwin CT, Bowirrat A, Waraska K, Inzelberg R, Friedland RP, Farrer LA: Association of polymorphisms in the angiotensin-converting enzyme gene with Alzheimer disease in an Israeli Arab community. Am J Hum Genet 2006, 78:871877.

18. Schjeide BM, McQueen MB, Mullin K, Divito J, Hogan MF, Parkinson M, Hooli B, Lange C, Blacker D, Tanzi RE, Bertram L: Assessment of Alzheimer's disease case-control associations using family-based methods. Neurogenetics 2009, 10:19-25.

19. Edwards TL, Pericak-Vance M, Gilbert JR, Haines JL, Martin ER, Ritchie MD: An association analysis of Alzheimer disease candidate genes detects an ancestral risk haplotype clade in ACE and putative multilocus association between ACE, A2M, and LRRTM3. Am J Med Genet B Neuropsychiatr Genet 2008 [Epub ahead of print].

20. Li H, Wetten S, Li L, St Jean PL, Upmanyu R, Surh L, Hosford D, Barnes MR, Briley JD, Borrie M, Coletta N, Delisle R, Dhalla D, Ehm MG, Feldman HH, Fornazzari L, Gauthier S, Goodgame N, Guzman D, Hammond S, Hollingworth P, Hsiung GY, Johnson J', Kelly DD, Keren R, Kertesz A, King KS, Lovestone S, Loy-English I, Matthews PM, et al:: Candidate single-nucleotide polymorphisms from a genomewide association study of Alzheimer disease. Arch Neurol 2008, 65:45-53.

21. Miners JS, Ashby E, Harrison R, Speedy E, Baig S, Prince JA, Love S, Kehoe PG: Angiotensin-converting enzyme levels and activity in Alzheimer's disease: differences in brain and CSF ACE and association with ACE1 genotypes. Am J Translational Res 2009, 1:163-177.

22. Miners JS, Ashby E, Van Helmond Z, Chalmers KA, Palmer LE, Love S, Kehoe PG: Angiotensin-converting enzyme (ACE) levels and activity in Alzheimer's disease, and relationship of perivascular ACE-1 to cerebral amyloid angiopathy. Neuropathol Appl Neurobiol 2008, 34:181-193.

23. Savaskan $\mathrm{E}$ : The role of the brain renin-angiotensin system in neurodegenerative disorders. Curr Alzheimer Res 2005, 2:29-35.

24. Kehoe PG: The renin-angiotensin-aldosterone system and Alzheimer s disease? J Renin Angiotensin Aldosterone Syst 2003, 4:80-93.

25. Zubenko GS, Volicer L, Direnfeld LK, Freeman M, Langlais PJ, Nixon RA: Cerebrospinal fluid levels of angiotensin-converting enzyme in Alzheimer's disease, Parkinson's disease and progressive supranuclear palsy. Brain Res 1985, 328:215-221.

26. Zubenko GS, Marquis JK, Volicer L, Direnfeld LK, Langlais PJ, Nixon RA: Cerebrospinal fluid levels of angiotensin-converting enzyme, acetylcholinesterase, and dopamine metabolites in dementia associated with Alzheimer's disease and Parkinson's disease: a correlative study. Biol Psychiatry 1986, 21: 1365-1381.

27. Konings $\mathrm{CH}$, Kuiper MA, Scheltens P, Grijpma AM, van Pelt W, Wolters EC: Re-evaluation of cerebrospinal fluid angiotensinconverting enzyme activity in patients with 'probable' Alzheimer's disease. Eur J Clin Chem Clin Biochem 1993, 31: 495-497.

28. Nielsen HM, Londos E, Minthon L, Janciauskiene SM: Soluble adhesion molecules and angiotensin-converting enzyme in dementia. Neurobiol Dis 2007, 26:27-35.

29. Lendon CL, Thaker U, Harris JM, McDonagh AM, Lambert JC, Chartier-Harlin MC, Iwatsubo T, Pickering-Brown SM, Mann DM: The angiotensin 1-converting enzyme insertion (I)/deletion (D) polymorphism does not influence the extent of amyloid or tau pathology in patients with sporadic Alzheimer's disease. Neurosci Lett 2002, 328:314-318.

30. Danilov S, Savoie F, Lenoir B, Jeunemaitre X, Azizi M, Tarnow L, Alhenc-Gelas F: Development of enzyme-linked immunoassays for human angiotensin I converting enzyme suitable for large-scale studies. J Hypertens 1996, 14:719-727. 
31. Vardy ER, Rice PJ, Bowie PC, Holmes JD, Catto AJ, Hooper NM: Plasma Angiotensin-converting enzyme in Alzheimer's disease. J Alzheimers Dis 2009, 16:609-618.

32. Toropygin IY, Kugaevskaya EV, Mirgorodskaya OA, Elisseeva YE, Kozmin YP, Popov IA, Nikolaev EN, Makarov AA, Kozin SA: The $\mathrm{N}$-domain of angiotensin-converting enzyme specifically hydrolyzes the Arg-5-His-6 bond of Alzheimer's Abeta-(1-16) peptide and its isoAsp-7 analogue with different efficiency as evidenced by quantitative matrix-assisted laser desorption/ionization time-of-flight mass spectrometry. Rapid Commun Mass Spectrom 2008, 22:231-239.

33. Zou K, Yamaguchi H, Akatsu H, Sakamoto T, Ko M, Mizoguchi K, Gong JS, Yu W, Yamamoto T, Kosaka K, Yanagisawa K, Michikawa $M$ : Angiotensin-converting enzyme converts amyloid beta-protein 1-42 (Abeta(1-42)) to Abeta(1-40), and its inhibition enhances brain Abeta deposition. J Neurosci 2007, 27:8628-8635.

34. Wang J, Ho L, Chen L, Zhao Z, Zhao W, Qian X, Humala N, Seror I, Bartholomew S, Rosendorff C, Pasinetti GM: Valsartan lowers brain beta-amyloid protein levels and improves spatial learning in a mouse model of Alzheimer disease. $J$ Clin Invest 2007, 117:3393-3402.

35. Takeda S, Sato N, Rakugi H, Morishita R: Improvement of cognitive decline and cerebrovascular dysfunction in a mouse model of Alzheimer's disease by angiotensin receptor blocker, Olmesartan. Alzheimer's Dementia 2008, 4:T479.

36. Sun X, Becker M, Pankow K, Krause E, Ringling M, Beyermann M, Maul B, Walther T, Siems W-E: Catabolic attacks of membranebound angiotensin-converting enzyme on the $\mathrm{N}$-terminal part of species-specific amyloid-[beta] peptides. Eur J Pharmacol 2008, 588:18-25.

37. Gard PR: Angiotensin as a target for the treatment of Alzheimer's disease, anxiety and depression. Expert Opin Ther Targets 2004, 8:7-14.

38. Barnes JM, Barnes NM, Costall B, Coughlan J, Kelly ME, Naylor RJ, Tomkins DM, Williams TJ: Angiotensin-converting enzyme inhibition, angiotensin, and cognition. J Cardiovasc Pharmacol 1992, 19(Suppl 6):S63-71.

39. Hamdi HK, Castellon R: A genetic variant of ACE increases cell survival: a new paradigm for biology and disease. Biochem Biophys Res Commun 2004, 318:187-191.

40. Chai SY, Yeatman HR, Parker MW, Ascher DB, Thompson PE, Mulvey HT, Albiston AL: Development of cognitive enhancers based on inhibition of insulin-regulated aminopeptidase. BMC Neurosci 2008, 9(Suppl 2):S14.

41. Peters R, Beckett N, Forette F, Tuomilehto J, Clarke R, Ritchie C, Waldman A, Walton I, Poulter R, Ma S, Comsa M, Burch L, Fletcher A, Bulpitt C; HYVET investigators: Incident dementia and blood pressure lowering in the Hypertension in the Very Elderly Trial cognitive function assessment (HYVET-COG): a double-blind, placebo controlled trial. Lancet Neurol 2008, 7: 683-689.

42. Rosenberg PB, Mielke MM, Tschanz J, Cook L, Corcoran C, Hayden KM, Norton M, Rabins PV, Green RC, Welsh-Bohmer KA, Breitner JC, Munger R, Lyketsos CG: Effects of cardiovascular medications on rate of functional decline in Alzheimer disease. Am J Geriatr Psychiatry 2008, 16:883-892.

43. Fogari R, Mugellini A, Zoppi A, Derosa G, Pasotti C, Fogari E, Preti $P$ : Influence of losartan and atenolol on memory function in very elderly hypertensive patients. J Hum Hypertens 2003, 17:781-785.

44. Tedesco MA, Ratti G, Di Salvo G, Natale F: Does the angiotensin II receptor antagonist losartan improve cognitive function? Drugs Aging 2002, 19:723-732.

45. Hajjar I, Catoe H, Sixta S, Boland R, Johnson D, Hirth V, Wieland $D$, Eleazer $P$ : Cross-sectional and longitudinal association between antihypertensive medications and cognitive impairment in an elderly population. J Gerontol A Biol Sci Med Sci 2005, 60:67-73.

46. Wolozin B, Lee A, Lee A, Whitmer R, Kaziz L: Use of angiotensin receptor blockers is associated with lower incidence and progression of Alzheimer's disease. Alzheimer's Dementia 2008, 4:T118.

47. Cushman DW, Wang FI, Fung WC, Harvey CM, DeForrest JM: Differentiation of angiotensin-converting enzyme (ACE) inhibitors by their selective inhibition of ACE in physiologically important target organs. Am J Hypertens 1989, 2:294-306.
48. Weiner MF Bonte FJ, Tintner $R$, Ford N, Svetlik D, Riall T: ACE inhibitor lacks acute effect on cognition or brain blood flow in Alzheimer's disease. Drug Dev Res 1992, 26:467-471.

49. Sudilovsky A, Cutler NR, Sramek JJ, Wardle T, Veroff AE, Mickelson W, Markowitz J, Repetti S: A pilot clinical trial of the angiotensin-converting enzyme inhibitor ceranapril in Alzheimer disease. Alzheimer Dis Assoc Disord 1993, 7:105111.

50. Louis WJ, Mander AG, Dawson M, O'Callaghan C, Conway EL: Use of computerized neuropsychological tests (CANTAB) to assess cognitive effects of antihypertensive drugs in the elderly. Cambridge Neuropsychological Test Automated Battery. J Hypertens 1999, 17:1813-1819.

51. Haulica I, Bild W, Serban DN: Angiotensin peptides and their pleiotropic actions. J Renin Angiotensin Aldosterone Syst 2005, 6:121-131. 